\title{
Empathy and Prosocial Behavior in Siblings of Children with Autism Spectrum Disorder: a Systematic Review
}

\author{
Stian Orm ${ }^{1,2}$ (D) $\cdot$ Torun Vatne $^{2} \cdot$ Theodore S. Tomeny $^{3} \cdot$ Krister Fjermestad $^{1,2}$ (D) \\ Received: 10 July 2020 / Accepted: 17 March 2021 / Published online: 9 April 2021 \\ (C) The Author(s) 2021
}

\begin{abstract}
Siblings of children with ASD have, as a group, more autistic traits than typically developing individuals. A high prevalence of autistic traits may (or may not) include lower scores on measures of empathy and prosocial behavior compared with typically developing individuals. The purpose of this study was to conduct a systematic review of studies of empathy and prosocial behavior in siblings of individuals with ASD. We conducted a comprehensive literature search of studies published until March 2020. We identified 16 studies with a total of 1066 siblings that met inclusion criteria. Based on the review, we conclude that the current literature suggests that siblings of individuals with ASD exhibit normative empathic abilities and prosocial behavior.
\end{abstract}

Keywords Empathy $\cdot$ Prosocial behavior $\cdot$ Autism spectrum disorders $\cdot$ Siblings $\cdot$ Broader autism phenotype

Autism spectrum disorder (ASD) affects around 1.5\% of children (Lyall et al., 2017). The main characteristics of ASD are impairments in social communication and interaction, and restrictive and repetitive behavior and interests (American Psychiatric Association, 2013). These characteristics are thought to be related to atypical development in domains like social cognition (Tager-Flusberg, 2007), executive functions (Hill, 2004), and temporal cognition (Boucher et al., 2007). In addition to atypical social and cognitive development, children with ASD often have concurrent mental health and/or behavioral problems, including increased risk of depression, anxiety, oppositional behavior, hyperactivity, and sleep problems (Carmassi et al., 2019; Pezzimenti et al., 2019; Simonoff et al., 2008).

According to family systems theory, all family members influence each other reciprocally (Dore, 2008). Around $80 \%$ of children have one or more siblings (Dirks et al.,

Stian Orm

stianorm@hotmail.com

1 Department of Psychology, University of Oslo, Oslo, Norway

2 Frambu Resource Center for Rare Disorders, Sandbakkveien 18, 1404 Siggerud, Norway

3 Department of Psychology, The University of Alabama, Tuscaloosa, AL, USA
2015), and the sibling relationship is one of life's longest lasting relations. Typically developing (TD) children spend a lot of time with siblings, possibly even more than with parents (Buist et al., 2013; Dirks et al., 2015). Hence, the sibling relationship represents an important component of children's social, emotional, and cognitive development (Buist et al., 2013; Dirks et al., 2015). The combination of atypical development and concurrent mental health and behavioral problems that may accompany ASD can pose risks for siblings (Shivers et al., 2019). A meta-analysis of psychosocial functioning among siblings of children with ASD found that these siblings had significantly lower psychosocial functioning than siblings of children with other developmental disorders and TD controls, and were at higher risk of depression and anxiety (Shivers et al., 2019).

Factors that may influence the psychosocial functioning of siblings of children with ASD include differential treatment/ attention from parents, behavioral problems displayed by the child with ASD (e.g., aggression toward siblings), and negative reactions from others (Haukeland et al., 2015; Tudor et al., 2018). Whereas sibling relationships typically include much social interaction, pretend play, competitiveness, warmth, and intimacy, this is not always the case when one sibling has ASD. For example, Kaminsky and Dewey (2001) found that relationships between children with ASD and their siblings were characterized by lower intimacy and warmth compared with other sibling relationships. 
For siblings of children with ASD, the risk of psychosocial difficulties is thought to be twofold (e.g., Orsmond \& Seltzer, 2009). First, ASD is highly heritable, with heritability mostly due to common genetic variants (Gaugler et al., 2014; Tick et al., 2016). Thus, siblings of children with ASD, who on average share $50 \%$ of genes with the child with ASD, are at increased genetic risk of ASD or autistic traits. Many siblings of children with ASD have elevated levels of autistic traits without meeting the diagnostic criteria; this is often called the broader autism phenotype (Charman et al., 2017; Ingersoll \& Wainer, 2014). The broader autism phenotype includes higher levels of autistic-type social difficulties and executive dysfunction among relatives of individuals with ASD, including siblings (see Ingersoll \& Wainer, 2014 for review).

Much sibling research has focused on mental health, but less research has examined how growing up with a brother or sister with ASD affects siblings' social development. Older siblings often function as role models for younger siblings (Dirks et al., 2015). An important part of children's social and emotional development is the development of empathy and prosocial behavior. Empathy can be seen as a multidimensional construct comprising at least two dimensions; affective empathy and cognitive empathy. Affective empathy is defined as the emotional response triggered by seeing another person in emotional distress (Baron-Cohen \& Wheelwright, 2004). In contrast, cognitive empathy is the cognitive understanding of other people's emotions, which is related to and partially overlapping with theory of mind (Baron-Cohen \& Wheelwright, 2004). Prosocial behavior is defined as voluntary behavior aimed at benefiting or helping others (Eisenberg et al., 2007). Empathy, both the affective response and cognitive understanding, is closely related to prosocial behavior as an emotion that triggers prosocial behaviors (Eisenberg et al., 2007; Telle \& Pfister, 2016; Zhao et al., 2019).

When an additional child is born into a family, parents have the opportunity to teach the older sibling about caretaking, sharing, and helping. Likewise, the younger child's empathy and prosocial development can be supported by scaffolding, modeling, and norm setting provided by the older sibling (Hughes et al., 2018). Parental efforts to teach their children empathy and prosocial behavior often include encouragement to display empathy and prosocial behavior towards siblings. Typically, this creates more teaching and learning opportunities for children with siblings compared with children without siblings (Hughes et al., 2018). However, several studies have demonstrated that the relationships between children with ASD and their TD siblings are characterized by less prosocial behavior compared with other sibling relationships (Kaminsky \& Dewey, 2001; Knott et al., 1995, 2007).

Individuals with ASD display lower scores on conventional measures of empathy and prosocial behavior (Harmsen, 2019; Russell et al., 2012; Song et al., 2019). Some studies have found that individuals with ASD primarily display difficulties with cognitive empathy, whereas affective empathy appears to be comparable with that of TD individuals (e.g., Deschamps et al., 2014; Rogers et al., 2007). Lower scores on cognitive empathy could be due to differences in how individuals with ASD experience and display empathy (e.g., Fletcher-Watson \& Bird, 2020). In addition, it seems that typically developing adults have difficulties with understanding the emotions displayed by individuals with ASD (Sheppard et al., 2016), suggesting a two-way, double-empathy problem (Milton, 2012). Notwithstanding these challenges sometimes experienced by social partners, evidence suggests that, in general, ASD is linked to difficulties with at least some domains of empathy and prosocial behavior (Harmsen, 2019; Song et al., 2019). In a general population sample, Zhao et al. (2019) found that empathy partially mediated the relationship between autistic traits and prosocial behavior. That is, more autistic traits were related to less empathy, which again was related to less prosocial behavior. Thus, the empathic and prosocial development of siblings of children with ASD may be affected in two ways: (1) through increased genetic risk of autistic traits with associated empathic and prosocial difficulties and (2) through more limited opportunities to learn and practice empathy and prosocial behavior in the sibling relationship with the child with ASD.

Alternatively, other research has shown that the experience of being a sibling of a brother or sister with a chronic disorder other than ASD can enhance empathy and prosocial behavior. For example, two studies compared siblings of children with physical disabilities (PD) to controls and found that siblings of children with PD scored significantly higher on measures of empathy and prosocial behavior (Perenc et al., 2015; Perenc \& Pęczkowski, 2018). These findings contrast with the potential negative impacts such experiences can have on mental health and remind us that the assumption that siblings automatically will experience negative outcomes sometimes is wrong. Thus, there are at least two reasons why the topic of empathy and prosocial behavior deserves further study among siblings of children with ASD. First, such knowledge can provide important information about risk and protective factors in siblings, which can be targeted in interventions. Second, such knowledge can inform the field about how genetic risk of ASD and environmental risk of growing up with a child with ASD affects social developmental outcomes.

Three hypotheses can be presented regarding empathy and prosocial behavior in siblings of children with ASD. The first is that these siblings have impaired empathy and low levels of prosocial behavior due to shared genetic risk and/or the experience of living together with a child with ASD. The second is that these siblings display enhanced empathy and prosocial behavior due to the experience of living with a brother or sister with special needs. A third option is that the null hypothesis holds true, and these siblings display the same levels of 
empathy and prosocial behavior as other children. The field has yet to establish which hypothesis is most supported. Therefore, our goal was to conduct a systematic literature review of studies of empathy and/or prosocial behavior in siblings of children with ASD inspired by the following research question: Do siblings of children with ASD display lower, comparable, or higher levels of empathy and prosocial behavior compared to children who do not have siblings with $A S D$ ? We chose typically developing children without a sibling with ASD as controls because this is the most natural comparison group when examining developmental outcomes in siblings of children with ASD. Further, we focus only on siblings aged 0 to 18 years, since adult sibling relationships are considerably different from childhood sibling relationships (e.g., Tomeny et al., 2017).

\section{Method}

We followed the Preferred Reporting Items for Systematic reviews and Meta-Analyses (the PRISMA statement), as far as the guidelines apply to a systematic review of crosssectional studies (Moher et al., 2009).

\section{Data Sources and Search Strategy}

We consulted the following databases: PsycINFO, PubMed, and Web of Science. The search was conducted in March 2020 (ending 23rd March), using the following search string: sibli* AND (autis* OR Asperger*) AND (prosocial* OR empath*)". There were no limits on publication year. The initial search revealed 110 records. Fifty-one remained after limiting to English, peer-reviewed articles and removing duplicates (see Fig. 1). We also performed a comprehensive manual search by consulting previous reviews (Meadan et al., 2010; Shivers et al., 2019), reference lists of included papers, and papers known to the authors. Through the manual search, we identified six additional relevant papers.

\section{Procedure and Study Selection}

\section{Inclusion and Exclusion Criteria}

To be included, articles had to (a) be published in a peerreviewed journal, (b) report original findings on prosocial behavior and/or empathy (i.e., include a specific measure of at least one of these constructs) in siblings (age $\leq 18$ years) of individuals with ASD, and (c) include a comparison condition (i.e., a control group or comparison with established norms). Exclusionary criteria included articles published in languages other than English and qualitative studies.

\section{Procedure}

Two reviewers independently screened titles and abstracts of all 51 articles from the electronic search. After this screening, we then screened the full text of 19 articles to assess eligibility, of which ten were included in the final review (see Fig. 1). The inter-rater agreement for inclusion was very high (Cohen's kappa $=.84)$. Disagreements were resolved through discussion. The six studies identified through the manual search were assessed for eligibility by one author and confirmed by another. Following the manual search, a grand total of 16 studies met the inclusion criteria and were included in the full review. Seven of the studies examined empathy and 10 of the studies examined prosocial behavior (i.e., one study examined both empathy and prosocial behavior).

\section{Data Extraction and Quality Assessment}

The following data were extracted from the included studies: authors, publication year, country of origin, study design, participant characteristics (age and gender), recruitment method, type of comparison condition, measurements, and main results including effect sizes and $p$-values. If the article did not report effect size(s), we calculated Cohens $d$ from data provided in the article using the following formula $\left(M_{\mathrm{Group} 1}-M_{\mathrm{Group} 2}\right) /$ $\mathrm{SD}_{\text {pooled }}$ (Cohen, 1992).

We conducted quality assessments using the NewcastleOttawa Scale (NOS) for case-control studies (Wells et al., 2019). This scale includes eight items that assess study quality within the domains of representativeness and sample selection, comparability of cases and controls, assessment procedures, and response rates. The maximum possible score is nine and the lowest is zero. The NOS case-control scale has shown fair to good interrater reliability, excellent test-retest reliability, and weak to moderate concurrent validity in previous studies (Moskalewicz \& Oremus, 2020; Oremus et al., 2012). In our study, two reviewers independently rated quality. Agreement between raters was excellent, intra-class correlation $($ ICC; two-way random $)=.88$ (Cicchetti, 1994). Disagreements were resolved through discussion.

\section{Results}

See Tables 1 and 2 for an overview of the reviewed studies.

\section{Descriptives}

\section{Participants}

Data from a total of 1066 siblings of children with ASD were included across the studies. Sibling age ranged from 1 to 18 years. Samples ranged from $37.3 \%$ to $64.0 \%$ male. 



Fig. 1 Adapted PRISMA flow chart of the study selection process (Moher et al., 2009)

\section{Measures and Informants}

With two exceptions (McDonald et al., 2017; Tsang et al., 2016), the reviewed studies measured either prosocial behavior or empathy via only a single measure of the outcome of interest. McDonald et al. (2017) and Tsang et al. (2016) each used both a behavioral measure and parent-report. The measures in McDonald et al. (2017) included assessment of both empathy and prosocial behavior.

We divided measure types into three main categories: (1) behavioral observation paradigms in which children witnessed an adult or child in distress and observers coded 





their empathic and/or prosocial responses, (2) parent- or selfreport questionnaires, and (3) observer-rated tests of empathic reasoning.

Studies $(k=5)$ based on behavioral measures used similar observation situations in which infants and toddlers were exposed to an adult pretending to hurt his/her finger or foot, or a crying baby (Campbell et al., 2015, 2017; Hutman et al., 2010; McDonald et al., 2017; Tsang et al., 2016). These paradigms were used to measure empathy. The studies used masked coders and interclass correlations between raters ranged from acceptable to excellent (ICC $=.73$ to .95 ).

Studies $(k=12)$ based on questionnaires often used the Strengths and Difficulties Questionnaire (SDQ; Goodman, $1997 ; k=10$ ), which includes a prosocial behavior subscale. The SDQ comprises a parent-report version for children aged 4 to 16 years, and a self-report version for children $\geq 11$ years. Two studies utilized self-report (Hastings \& Petalas, 2014; Tsai et al., 2016), while the others utilized parent-report. Questionnaires used to measure empathy included the Interpersonal Reactivity Index (self-report; Davis, 1983), Griffith Empathy Measure (parent-report; Dadds et al., 2008), and the Conscience Questionnaire (parent-report; Kochanska et al., 1994). Across studies, three used self-report, while the rest used parent-report.

Only one study was based on a test of empathy, as measured by the Unexpected Outcome Test (Eyuboglu et al., 2018). The Unexpected Outcome Test involves reasoning about the emotional states of others when these emotions are out of context (cognitive empathy). In the test, participants get described a situation where the emotional state of the protagonist is out of place (e.g., angry when going to a movie with a friend) and asked to provide additional information to solve the disparity (Dyck et al., 2001).

\section{Comparison Conditions}

Most studies used a control group comprising children who did not have siblings with ASD. Eight studies compared siblings to population-norms from a general child and adolescent population in the given country (i.e., SDQ norm data).

\section{Empathy in Siblings of Children with ASD}

Among the seven studies investigating empathy, four observed significantly lower empathy for siblings of children with ASD compared with controls, at least at some ages (Campbell et al., 2015, 2017; Eyuboglu et al., 2018). Three found no significant difference between siblings and controls (Park et al., 2012; Tsang et al., 2016), whereas two studies observed higher empathy in siblings in one or more domain(s) (McDonald et al., 2017; Shivers, 2019). Campbell et al. (2017) conducted a longitudinal study where significant differences between younger siblings of children with ASD and 


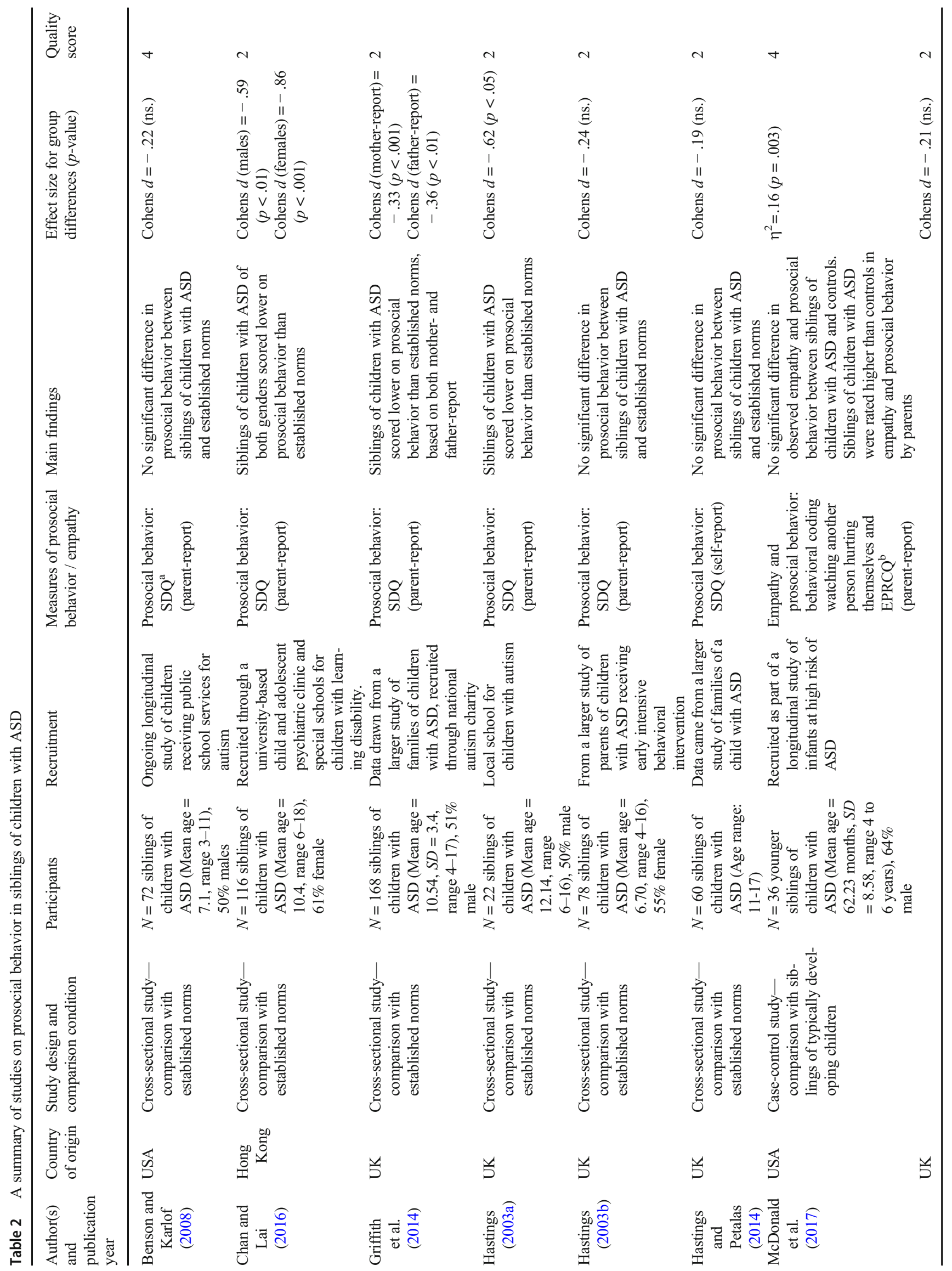




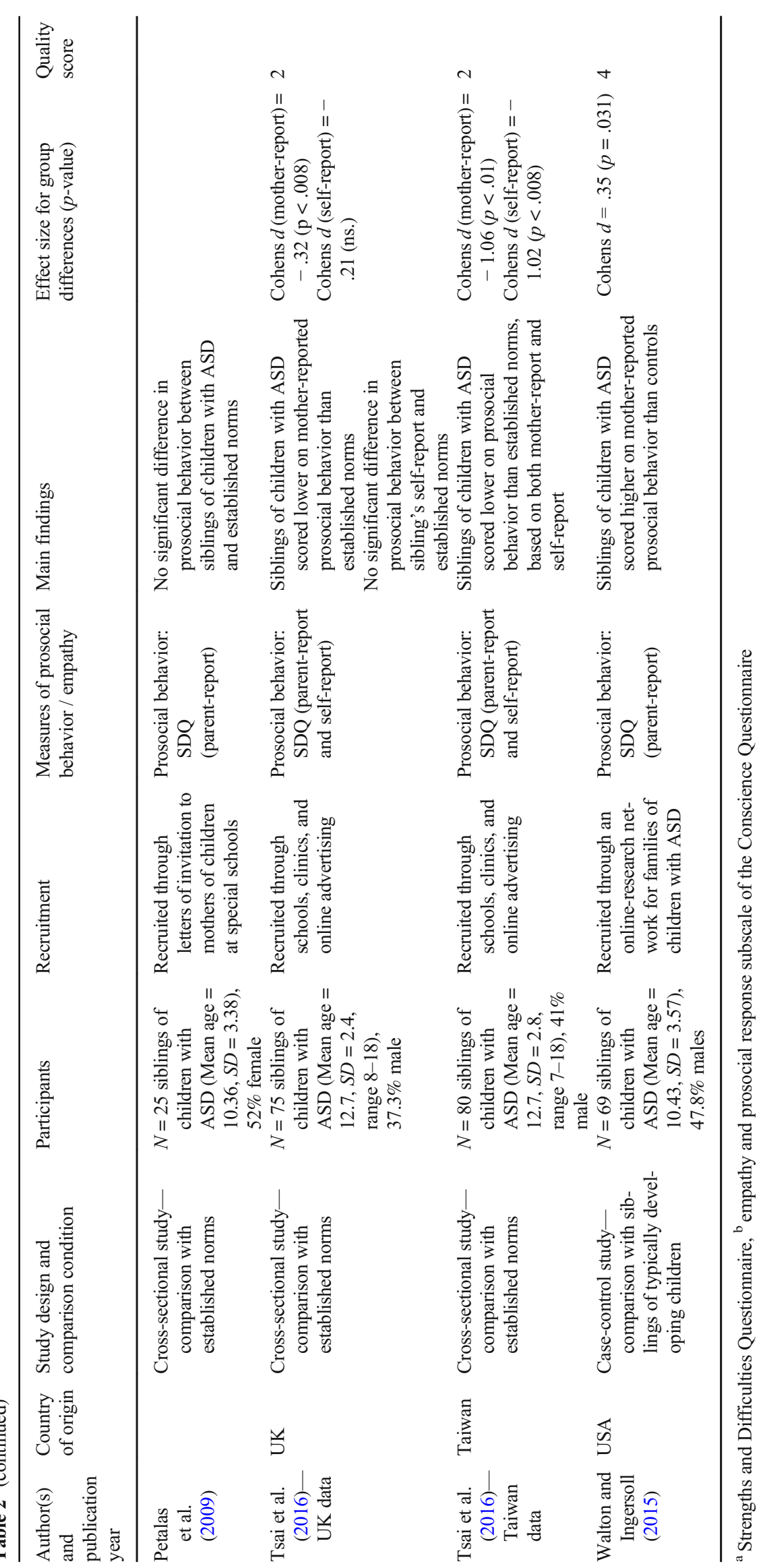


TD controls were found at 22 and 28 months of age, but this difference diminished by 34 months of age. When excluding siblings who go on to receive an ASD diagnosis early in life, there is little evidence of impaired empathy beyond 3 years of age in siblings of children with ASD (e.g., Campbell et al., 2017; Hutman et al., 2010; McDonald et al., 2017).

\section{Prosocial Behavior in Siblings of Children with ASD}

Of the 10 studies investigating prosocial behavior, four studies found less prosocial behavior in siblings of children with ASD compared with controls (Chan \& Lai, 2016; Griffith et al., 2014; Hastings, 2003a; Tsai et al., 2016). Four studies found no difference between siblings and controls (Benson \& Karlof, 2008; Hastings, 2003b; Hastings \& Petalas, 2014; Petalas et al., 2009). Two studies found more prosocial behavior in siblings of children with ASD on at least one measure (McDonald et al., 2017; Walton \& Ingersoll, 2015). McDonald et al. (2017) did not find a significant difference between siblings of children with ASD and controls on the behavioral measure of empathy and prosocial behavior, but parents of siblings reported significantly higher empathy and prosocial behavior than parents of controls.

Tsai et al. (2016) included siblings from the UK and Taiwan and compared siblings' SDQ scores with British and Chinese norms, respectively. Siblings of children with ASD from the UK scored significantly lower than populationnorms on parent-reported prosocial behavior with no significant difference in self-reported prosocial behavior. In contrast, siblings of children with ASD from Taiwan scored significantly lower on parent- and self-reported prosocial behavior relative to norms. The UK sample effect size difference was small, whereas the Taiwan sample difference was large.

\section{Quality Assessment and Risk of Bias}

Our quality assessment (Newcastle-Ottawa Scale) showed considerable variability in quality among studies. The scores ranged from 2 to 7 points on the 0 -to- 9 point scale. We scored studies of empathy higher $(k=7, \mathrm{M}=5.00 \mathrm{SD}=1.15)$ than studies of prosocial behavior $(k=10, \mathrm{M}=2.60, \mathrm{SD}=0.97)$. The studies focused on prosocial behavior rarely secured comparability between cases and controls (i.e., the use of population-norms prevented comparison of samples on demographic variables). Further, studies of prosocial behavior used almost exclusively self-report measures, lacked independent validation of cases (i.e., validation of ASD diagnosis in brother/sister), and did not obtain representative samples (i.e., random samples or all cases in a defined catchment area). More of the empathy studies included independent validation of ASD diagnoses, behavioral measures of outcomes, and comparability between cases and controls (i.e., covariates included in the analyses or groups matched on background measures).
However, none of the empathy studies were rated to recruit representative samples of cases, and none reported response rates or non-responder characteristics.

\section{Discussion}

The purpose of this review was to collate research examining whether siblings of children with ASD display lower, comparable, or heightened levels of empathy and prosocial behavior when compared with children who do not have siblings with ASD. Authors of previous studies have repeatedly noted the considerable heterogeneity among studies of siblings of children with ASD and the inconclusiveness due to the mixed findings (e.g., Meadan et al., 2010; Shivers et al., 2019; Tomeny et al., 2012). This review supports this message with our findings of considerable heterogeneity in methodology, samples, and results of studies on empathy and prosocial behavior in siblings of children with ASD (Meadan et al., 2010; Shivers et al., 2019).

With regard to empathy, the reviewed studies suggest that siblings of children with ASD likely have normative empathy development, particularly as empathy evolves beyond the toddler years. Only one study found lower empathy in siblings over age 3 years (Eyuboglu et al., 2018). However, the extent to which the Unexpected Outcomes Test (UOT), as featured in Eyuboglu et al. (2018), measures empathy can be questioned because the UOT is cognitively oriented toward reasoning and knowledge about emotions, and the original authors describe it as a subtest of emotion recognition (Dyck, 2012; Dyck et al., 2001). Whereas some authors consider emotion recognition and understanding to be the same as cognitive empathy (e.g., Westby \& Robinson, 2014), a consensus definition of empathy does not exist (Fletcher-Watson \& Bird, 2020) and the UOT may neglect to detect components of empathy. The other measures used to assess empathy in the reviewed studies were seemingly more established empathy measures. Specifically, the behavioral measures are similar to or based on measures used in other developmental research (e.g., Nichols et al., 2015; Sigman et al., 1992; Zahn-Waxler et al., 1992), and the remaining parent- and self-report measures have been reported to be reliable and valid (Dadds et al., 2008; Gilet et al., 2013; Kochanska et al., 1994).

Some studies have demonstrated heightened empathy in siblings of children with ASD (e.g., McDonald et al., 2017; Shivers, 2019), suggesting that some siblings may benefit from their experiences of having a brother or sister with ASD, and develop understanding and compassion. Intact empathic abilities in siblings of children with ASD suggest that the presence of more autistic traits on a group level does not necessarily include deficits in empathy like those characteristic of ASD (Harmsen, 2019; Song et al., 2019). However, future studies should examine whether levels of autistic traits 
and empathy are related in siblings. As noted by Shivers (2019), diagnostic criteria and the tools used to assess for ASD do not always include empathy deficits, but rather focus on general social skills and social responsiveness. Further, high levels of autistic traits in one area (e.g., executive dysfunction) do not always imply high levels of autistic traits in another area (e.g., difficulties with empathy). Thus, autistic traits among siblings of children with ASD are not necessarily incompatible with intact empathic abilities.

A recent area of research important to the understanding of empathy in individuals with ASD and their siblings is alexithymia. Alexithymia, which includes difficulties with interpreting one's own emotions, is often observed in individuals with ASD (Kinnaird et al., 2019). Moreover, higher levels of alexithymia are associated with lower levels of empathy (Grynberg et al., 2010). Similarly, a recent study found that alexithymia was associated with empathy, but autistic traits were a stronger predictor (Shah et al., 2019). Together, these studies underscore the need to consider both the levels of alexithymia and autistic traits in future investigations of empathy in siblings of children with ASD.

It has been proposed that siblings of children with ASD may develop more patience, understanding of individual needs, and perspective-taking abilities due to their everyday experiences with their brother or sister with ASD (e.g., Fjermestad et al., 2019; Shivers, 2019). A largely unexplored area of research is to what extent such experiences may buffer against increased genetic risk. In future studies, it would be interesting to examine how empathy, prosocial behavior, autistic traits, alexithymia, and polygenetic risk of ASD interact among siblings of children with ASD.

With regard to prosocial behavior, the results suggest considerable heterogeneity among siblings of children with ASD. Some studies indicate less prosocial behavior, others normative levels of prosocial behavior, and a few studies suggest higher levels of prosocial behavior in siblings of children with ASD. Based on the reviewed studies, no consistent developmental pattern was observed; the findings are mixed independent of which age group was investigated. It is likely that these highly inconsistent findings reflect the general heterogeneity of traits among siblings of children with ASD. For example, one study found that at the mean group level, siblings of individuals with ASD have intermediate levels of ASD symptoms, higher than TD controls but lower than individuals with ASD (Ruzich et al., 2016). Nevertheless, the authors also found that the sibling group could be divided into two subgroups: (1) one group with few autistic traits that was similar to TD controls and (2) a group with many autistic traits that was more similar to a group of individuals diagnosed with ASD. Thus, it could be that studies showing lower levels of prosocial behavior in siblings of children with ASD have an overrepresentation of the second subgroup, whereas studies showing higher levels of prosocial behavior among siblings of children with ASD have an overrepresentation of the first subgroup. Additional studies are needed to confirm or disconfirm this potential explanation.

A recent study found that more problem behavior in the child with ASD was related to a better sibling relationship (Tudor et al., 2018). The authors suggest that high levels of problem behavior displayed by the child with ASD are easily observable, which in turn makes the care needs of the child with ASD more obvious and promotes prosocial behavior from siblings. Alternatively, siblings of children with milder challenges may be less likely to engage in such scaffolding. Given the complex dynamics in families of children with ASD, future studies should investigate if characteristics of the family system serve as possible mediators or moderators of the relations between being a sibling of a child with ASD and empathy and prosocial behavior. Unsurprisingly, autistic traits in TD siblings have also been found to predict prosocial behavior and should be considered in analyses involving this domain (Petalas et al., 2012).

Unlike the empathy measures, the prosocial behavior measures were more consistent across studies. All but one study used the SDQ prosocial subscale (Goodman, 1997). Hence, differences in prosocial behavior across studies cannot be attributed to the use of different measures. This strengthens the notion of true heterogeneity among siblings and suggests that factors beyond simply being a sibling of a child with ASD are at play.

Notwithstanding, the SDQ (Goodman, 1997) includes a 5item subscale measuring relatively simple forms of prosocial behavior: (1) consideration of other people's feelings, (2) sharing with other children, (3) helping if someone's hurt, (4) being kind to younger children, and (5) volunteering to help others. Some of these behaviors (e.g., consideration of others' feelings) can tap into other concepts, such as empathy, and these statements do not cover more complex forms of prosocial behavior (e.g., giving someone a compliment to make them feel good; cooperating with others; engaging in volunteerism). The psychometric properties of the SDQ are considered acceptable in terms of test-retest reliability, internal consistency, and validity (Stone et al., 2010). However, the convergent validity of the SDQ has largely been established by (a) positive correlations between the problemoriented scales and measures of psychopathology and (b) negative correlations between the prosocial behavior subscale and measures of psychopathology (see Stone et al., 2010 for review). Although negative correlations with psychopathology suggest the prosocial subscale is a strength-based subscale, the extent to which this establishes the ability of the subscale's scores to adequately assess prosocial behavior is unclear. Because 9 out of 10 studies of prosocial behavior in siblings of children with ASD used the SDQ, future research would benefit from using multiple informants and assessing the convergent validity of the prosocial subscale when compared with 
other measures of prosocial behavior to provide points of comparison and allow for a more comprehensive assessment of the construct.

Moreover, our ability to make strong conclusions is tempered by methodological limitations across the reviewed studies. Our quality assessment indicates a need for studies with more comparable control groups, representative samples of cases, and more use of independent validation (i.e., beyond self-report) of the ASD diagnosis, as well as more comprehensive, and preferably behavioral, measures of empathy and prosocial behavior.

Researchers have developed and tested the efficacy of a number of different interventions targeting psychosocial adjustment in siblings of children with developmental disabilities (Haukeland et al., 2020; Jones et al., 2020). Our findings suggest that empathy and prosocial skills most likely do not need to be the primary foci of these interventions. For parents, these findings can be reassuring; siblings may be at general risk of psychosocial maladjustment but they seem to display as much empathy and prosocial behavior as their peers without a brother or sister with ASD. Furthermore, siblings' strengths in empathy and prosocial behavior can be beneficial for the entire family and contribute to more harmonious family dynamics. A theme for further research may be how siblings' empathy and prosocial behavior contribute to family dynamics and other family members' well-being.

Our review has limitations. First, we did not search for or included so-called grey literature, like theses and dissertations. We did not search for unpublished studies, so it is possible that studies with null findings have been neglected. Second, some of the reviewed studies of prosocial behavior did not explicitly aim to investigate prosocial behavior in siblings but used measures that included prosocial behavior as a subscale of broader measures of mental health or empathy. This means that few of the articles mentioned prosocial behavior in their title, abstract, or keywords, and thus, only four were identified through the initial systematic search whereas six were identified through the manual search (see Fig. 1). We performed a comprehensive manual search consulting previous reviews, reference lists of included papers, and papers known to the authors. Nevertheless, relevant papers could have been missed, and the conclusions in our review should be interpreted considering this possibility. Third, the applicability of the Newcastle-Ottawa quality assessment scale has been disputed (Stang, 2010); however, the scale is widely used and has demonstrated adequate psychometric properties (Moskalewicz \& Oremus, 2020; Oremus et al., 2012). Hence, the use of a standardized quality assessment specifically developed for case-control studies, which in the current study showed excellent reliability, could also be considered a strength.

To conclude, considering how the genetic and environmental risks of being a sibling of a child with ASD may affect sibling development (Ingersoll \& Wainer, 2014; Shivers, 2019), empathy and prosocial behavior are important domains that researchers, clinicians, and the affected families and siblings need to better understand. This review suggests that, overall, most siblings of children with ASD have intact empathy and prosocial behavior.

Funding Open access funding provided by University of Oslo (incl Oslo University Hospital).

\section{Declarations}

Conflict of Interest The authors declare no competing interests.

Open Access This article is licensed under a Creative Commons Attribution 4.0 International License, which permits use, sharing, adaptation, distribution and reproduction in any medium or format, as long as you give appropriate credit to the original author(s) and the source, provide a link to the Creative Commons licence, and indicate if changes were made. The images or other third party material in this article are included in the article's Creative Commons licence, unless indicated otherwise in a credit line to the material. If material is not included in the article's Creative Commons licence and your intended use is not permitted by statutory regulation or exceeds the permitted use, you will need to obtain permission directly from the copyright holder. To view a copy of this licence, visit http://creativecommons.org/licenses/by/4.0/.

\section{References}

American Psychiatric Association. (2013). Diagnostic and statistical manual of mental disorders (DSM-5). American Psychiatric Publishing.

Baron-Cohen, S., \& Wheelwright, S. (2004). The Empathy Quotient: an investigation of adults with Asperger syndrome or high functioning autism, and normal sex differences. Journal of Autism and Developmental Disorders, 34(2), 163-175. https://doi.org/10. 1023/B:JADD.0000022607.19833.00.

Benson, P. R., \& Karlof, K. L. (2008). Child, parent, and family predictors of latter adjustment in siblings of children with autism. Research in Autism Spectrum Disorders, 2(4), 583-600. https://doi.org/10. 1016/j.rasd.2007.12.002.

Boucher, J., Pons, F., Lind, S., \& Williams, D. (2007). Temporal cognition in children with autistic spectrum disorders: tests of diachronic thinking. Journal of Autism and Developmental Disorders, 37(8), 1413-1429. https://doi.org/10.1007/s10803-006-0285-9.

Buist, K. L., Deković, M., \& Prinzie, P. (2013). Sibling relationship quality and psychopathology of children and adolescents: a metaanalysis. Clinical Psychology Review, 33(1), 97-106. https://doi. org/10.1016/j.cpr.2012.10.007.

Campbell, S. B., Leezenbaum, N. B., Schmidt, E. N., Day, T. N., \& Brownell, C. A. (2015). Concern for Another's Distress in Toddlers at High and Low Genetic Risk for Autism Spectrum Disorder. Journal of Autism and Developmental Disorders, 45(11), 3594-3605. https://doi.org/10.1007/s10803-015-2505-7.

Campbell, S. B., Moore, E. L., Northrup, J., \& Brownell, C. A. (2017). Developmental Changes in Empathic Concern and SelfUnderstanding in Toddlers at Genetic Risk for Autism Spectrum Disorder. Journal of Autism and Developmental Disorders, 47(9), 2690-2702. https://doi.org/10.1007/s10803-017-3192-3. 
Carmassi, C., Palagini, L., Caruso, D., Masci, I., Nobili, L., Vita, A., \& Dell'Osso, L. (2019). Systematic review of sleep disturbances and circadian sleep desynchronization in autism spectrum disorder: toward an integrative model of a self-reinforcing loop. Frontiers in Psychiatry, 10. https://doi.org/10.3389/fpsyt.2019.00366.

Chan, J. Y. N., \& Lai, K. Y. C. (2016). Psychological adjustment of siblings of children with autism spectrum disorder in Hong Kong. East Asian Archives of Psychiatry; Aberdeen, 26(4), 141-147.

Charman, T., Young, G. S., Brian, J., Carter, A., Carver, L. J., Chawarska, K., Curtin, S., Dobkins, K., Elsabbagh, M., Georgiades, S., Hertz-Picciotto, I., Hutman, T., Iverson, J. M., Jones, E. J., Landa, R., Macari, S., Messinger, D. S., Nelson, C. A., Ozonoff, S., et al. (2017). Non-ASD outcomes at 36 months in siblings at familial risk for autism spectrum disorder (ASD): a baby siblings research consortium (BSRC) study. Autism Research, 10(1), 169-178. https://doi.org/10.1002/aur.1669.

Cicchetti, D. V. (1994). Guidelines, criteria, and rules of thumb for evaluating normed and standardized assessment instruments in psychology. Psychological Assessment, 6(4), 284-290.

Cohen, J. (1992). A power primer. Psychological Bulletin, 112(1), 155159. https://doi.org/10.1037//0033-2909.112.1.155.

Dadds, M. R., Hunter, K., Hawes, D. J., Frost, A. D. J., Vassallo, S., Bunn, P., Merz, S., \& Masry, Y. E. (2008). A measure of cognitive and affective empathy in children using parent ratings. Child Psychiatry and Human Development, 39(2), 111-122. https://doi. org/10.1007/s10578-007-0075-4.

Davis, M. H. (1983). Measuring individual differences in empathy: evidence for a multidimensional approach. Journal of Personality and Social Psychology, 44(1), 113-126. https://doi.org/10.1037/00223514.44.1.113.

Deschamps, P. K. H., Been, M., \& Matthys, W. (2014). Empathy and Empathy induced prosocial behavior in 6- and 7-year-olds with autism spectrum disorder. Journal of Autism and Developmental Disorders, 44(7), 1749-1758. https://doi.org/10.1007/s10803-0142048-3.

Dirks, M. A., Persram, R., Recchia, H. E., \& Howe, N. (2015). Sibling relationships as sources of risk and resilience in the development and maintenance of internalizing and externalizing problems during childhood and adolescence. Clinical Psychology Review, 42, 145155. https://doi.org/10.1016/j.cpr.2015.07.003.

Dore, M. M. (2008). Family Systems Theory. In B. A. Thyer, K. M. Snowers, \& C. N. Dulmus (Eds.), Comprehensive handbook of social work and social welfare: Vol. 2. Human behavior in the social environment (pp. 431-462). Wiley. https://doi.org/10.1002/ 9780470373705.chsw002018.

Dyck, M. J. (2012). The ability to understand the experience of other people: development and validation of the emotion recognition scales. Australian Psychologist, 47(1), 49-57. https://doi.org/10. 1111/j.1742-9544.2011.00047.x.

Dyck, M. J., Ferguson, K., \& Shochet, I. M. (2001). Do autism spectrum disorders differ from each other and from non-spectrum disorders on emotion recognition tests? European Child \& Adolescent Psychiatry, 10(2), 105-116. https://doi.org/10.1007/ s007870170033.

Eisenberg, N., Fabes, R. A., \& Spinrad, T. L. (2007). Prosocial development. In W. Damon \& R. M. Lerner (Eds.), Handbook of child psychology (Vol. 3). Wiley. https://doi.org/10.1002/ 9780470147658.chpsy0311.

Eyuboglu, M., Baykara, B., \& Eyuboglu, D. (2018). Broad autism phenotype: theory of mind and empathy skills in unaffected siblings of children with autism spectrum disorder. Psychiatry and Clinical Psychopharmacology, 28(1), 36-42. https://doi.org/10.1080/ 24750573.2017.1379714.

Fjermestad, K. W., Haukeland, Y. B., Mossige, S., \& Vatne, T. M. (2019). Children's perspectives on the experiences of their siblings with chronic disorders. Clinical Social Work Journal, 47(3), 290299. https://doi.org/10.1007/s10615-019-00705-3.

Fletcher-Watson, S., \& Bird, G. (2020). Autism and empathy: What are the real links? Autism, 24(1), 3-6. https://doi.org/10.1177/ 1362361319883506.

Gaugler, T., Klei, L., Sanders, S. J., Bodea, C. A., Goldberg, A. P., Lee, A. B., Mahajan, M., Manaa, D., Pawitan, Y., Reichert, J., Ripke, S., Sandin, S., Sklar, P., Svantesson, O., Reichenberg, A., Hultman, C. M., Devlin, B., Roeder, K., \& Buxbaum, J. D. (2014). Most genetic risk for autism resides with common variation. Nature Genetics, 46(8), 881-885. https://doi.org/10.1038/ng.3039.

Gilet, A.-L., Mella, N., Studer, J., Grühn, D., \& Labouvie-Vief, G. (2013). Assessing dispositional empathy in adults: a French validation of the Interpersonal Reactivity Index (IRI). Canadian Journal of Behavioural Science / Revue Canadienne Des Sciences Du Comportement, 45(1), 42-48. https://doi.org/10.1037/a0030425.

Goodman, R. (1997). The strengths and difficulties questionnaire: a research note. Journal of Child Psychology and Psychiatry, 38(5), 581-586. https://doi.org/10.1111/j.1469-7610.1997.tb01545.x.

Griffith, G. M., Hastings, R. P., \& Petalas, M. A. (2014). Brief report: fathers' and mothers' ratings of behavioral and emotional problems in siblings of children with autism spectrum disorder. Journal of Autism and Developmental Disorders, 44(5), 1230-1235. https:// doi.org/10.1007/s10803-013-1969-6.

Grynberg, D., Luminet, O., Corneille, O., Grèzes, J., \& Berthoz, S. (2010). Alexithymia in the interpersonal domain: a general deficit of empathy? Personality and Individual Differences, 49(8), 845850. https://doi.org/10.1016/j.paid.2010.07.013.

Harmsen, I. E. (2019). Empathy in autism spectrum disorder. Journal of Autism and Developmental Disorders, 49(10), 3939-3955. https:// doi.org/10.1007/s10803-019-04087-w.

Hastings, R. P. (2003a). Brief report: behavioral adjustment of siblings of children with autism. Journal of Autism and Developmental Disorders, 33(1), 99-104. https://doi.org/10.1023/A: 1022290723442 .

Hastings, R. P. (2003b). Behavioral adjustment of siblings of children with autism engaged in applied behavior analysis early intervention programs: the moderating role of social support. Journal of Autism and Developmental Disorders, 33(2), 141-150. https://doi.org/10. 1023/A:1022983209004.

Hastings, R. P., \& Petalas, M. A. (2014). Self-reported behaviour problems and sibling relationship quality by siblings of children with autism spectrum disorder. Child: Care, Health and Development, 40(6), 833-839. https://doi.org/10.1111/cch.12131.

Haukeland, Y. B., Fjermestad, K. W., Mossige, S., \& Vatne, T. M. (2015). Emotional experiences among siblings of children with rare disorders. Journal of Pediatric Psychology, 40(7), 712-720. https:// doi.org/10.1093/jpepsy/jsv022.

Haukeland, Y. B., Czajkowski, N. O., Fjermestad, K. W., Silverman, W. K., Mossige, S., \& Vatne, T. M. (2020). Evaluation of "SIBS", an intervention for siblings and parents of children with chronic disorders. Journal of Child and Family Studies. https://doi.org/10.1007/ s10826-020-01737-x.

Hill, E. L. (2004). Executive dysfunction in autism. Trends in Cognitive Sciences, 8(1), 26-32. https://doi.org/10.1016/j.tics.2003.11.003.

Hughes, C., McHarg, G., \& White, N. (2018). Sibling influences on prosocial behavior. Current Opinion in Psychology, 20, 96-101. https://doi.org/10.1016/j.copsyc.2017.08.015.

Hutman, T., Rozga, A., DeLaurentis, A. D., Barnwell, J. M., Sugar, C. A., \& Sigman, M. (2010). Response to distress in infants at risk for autism: a prospective longitudinal study. Journal of Child Psychology and Psychiatry, 51(9), 1010-1020. https://doi.org/10. 1111/j.1469-7610.2010.02270.x.

Ingersoll, B., \& Wainer, A. (2014). The broader autism phenotype. In F. R. Volkmar, S. J. Rogers, R. Paul, \& K. A. Pelphrey (Eds.), 
Handbook of Autism and Pervasive Developmental Disorders (Vol. 1, pp. 28-56). Wiley.

Jones, E. A., Fiani, T., Stewart, J. L., Neil, N., McHugh, S., \& Fienup, D. M. (2020). Randomized controlled trial of a sibling support group: mental health outcomes for siblings of children with autism. Autism, 1362361320908979. https://doi.org/10.1177/1362361320908979.

Kaminsky, L., \& Dewey, D. (2001). Siblings relationships of children with autism. Journal of Autism and Developmental Disorders, 31(4), 399-410. https://doi.org/10.1023/A:1010664603039.

Kinnaird, E., Stewart, C., \& Tchanturia, K. (2019). Investigating alexithymia in autism: a systematic review and meta-analysis. European Psychiatry, 55, 80-89. https://doi.org/10.1016/j.eurpsy. 2018.09.004.

Knott, F., Lewis, C., \& Williams, T. (1995). Sibling interaction of children with learning disabilities: a comparison of autism and Down's syndrome. Journal of Child Psychology and Psychiatry, 36(6), 965976. https://doi.org/10.1111/j.1469-7610.1995.tb01343.x.

Knott, F., Lewis, C., \& Williams, T. (2007). Sibling interaction of children with autism: development over 12 months. Journal of Autism and Developmental Disorders, 37(10), 1987-1995. https://doi.org/ 10.1007/s10803-006-0347-z.

Kochanska, G., DeVet, K., Goldman, M., Murray, K., \& Putnam, S. P. (1994). Maternal reports of conscience development and temperament in young children. Child Development, 65(3), 852-868. https://doi.org/10.1111/j.1467-8624.1994.tb00788.x.

Lyall, K., Croen, L., Daniels, J., Fallin, M. D., Ladd-Acosta, C., Lee, B. K., Park, B. Y., Snyder, N. W., Schendel, D., Volk, H., Windham, G. C., \& Newschaffer, C. (2017). The changing epidemiology of autism spectrum disorders. Annual Review of Public Health, 38(1), 81-102. https://doi.org/10.1146/annurev-publhealth-031816044318

McDonald, N. M., Murphy, H. G., \& Messinger, D. S. (2017). Empathic responding in preschool-aged children with familial risk for autism. Autism Research, 10(10), 1621-1628. https://doi.org/10.1002/aur. 1819.

Meadan, H., Stoner, J. B., \& Angell, M. E. (2010). Review of Literature related to the social, emotional, and behavioral adjustment of siblings of individuals with autism spectrum disorder. Journal of Developmental and Physical Disabilities, 22(1), 83-100. https:// doi.org/10.1007/s10882-009-9171-7.

Milton, D. E. M. (2012). On the ontological status of autism: The 'double empathy problem.'. Disability \& Society, 27(6), 883-887. https:// doi.org/10.1080/09687599.2012.710008.

Moher, D., Liberati, A., Tetzlaff, J., \& Altman, D. G. (2009). Preferred reporting items for systematic reviews and meta-analyses: The PRISMA statement. BMJ, 339. https://doi.org/10.1136/bmj.b2535.

Moskalewicz, A., \& Oremus, M. (2020). No clear choice between Newcastle-Ottawa Scale and Appraisal Tool for Cross-Sectional Studies to assess methodological quality in cross-sectional studies of health-related quality of life and breast cancer. Journal of Clinical Epidemiology, 120, 94-103. https://doi.org/10.1016/j.jclinepi.2019. 12.013 .

Nichols, S. R., Svetlova, M., \& Brownell, C. A. (2015). Toddlers' responses to infants' negative emotions. Infancy, 20(1), 70-97. https:// doi.org/10.1111/infa.12066.

Oremus, M., Oremus, C., Hall, G. B. C., McKinnon, M. C., \& ECT \&amp, \& Team, C. S. R. (2012). Inter-rater and test-retest reliability of quality assessments by novice student raters using the Jadad and Newcastle-Ottawa Scales. BMJ Open, 2(4), e001368. https://doi. org/10.1136/bmjopen-2012-001368.

Orsmond, G. I., \& Seltzer, M. M. (2009). Adolescent siblings of individuals with an autism spectrum disorder: testing a diathesis-stress model of sibling well-being. Journal of Autism and Developmental Disorders, 39(7), 1053-1065.

Park, S., Cho, S.-C., Cho, I. H., Kim, B.-N., Kim, J.-W., Shin, M.-S., Chung, U.-S., Park, T.-W., Son, J.-W., \& Yoo, H. J. (2012). Sex differences in children with autism spectrum disorders compared with their unaffected siblings and typically developing children. Research in Autism Spectrum Disorders, 6(2), 861-870. https:// doi.org/10.1016/j.rasd.2011.11.006.

Perenc, L., \& Pęczkowski, R. (2018). Cognitive and affective empathy among adolescent siblings of children with a physical disability. Disability and Health Journal, 11(1), 43-48. https://doi.org/10. 1016/j.dhjo.2017.08.008.

Perenc, L., Radochoński, M., \& Radochońska, A. (2015). Prosocial competencies among adolescent siblings of the physically disabled. Current Issues in Personality Psychology, 3(4), 195-202. https:// doi.org/10.5114/cipp.2015.53897.

Petalas, M. A., Hastings, R. P., Nash, S., Lloyd, T., \& Dowey, A. (2009). Emotional and behavioural adjustment in siblings of children with intellectual disability with and without autism. Autism, 13(5), 471483. https://doi.org/10.1177/1362361309335721.

Petalas, M. A., Hastings, R. P., Nash, S., Hall, L. M., Joannidi, H., \& Dowey, A. (2012). Psychological adjustment and sibling relationships in siblings of children with autism spectrum disorders: environmental stressors and the broad autism phenotype. Research in Autism Spectrum Disorders, 6(1), 546-555. https://doi.org/10.1016/ j.rasd.2011.07.015.

Pezzimenti, F., Han, G. T., Vasa, R. A., \& Gotham, K. (2019). Depression in youth with autism spectrum disorder. Child and Adolescent Psychiatric Clinics, 28(3), 397-409. https://doi.org/10. 1016/j.chc.2019.02.009.

Rogers, K., Dziobek, I., Hassenstab, J., Wolf, O. T., \& Convit, A. (2007). Who cares? revisiting empathy in Asperger syndrome. Journal of Autism and Developmental Disorders, 37(4), 709-715. https://doi. org/10.1007/s10803-006-0197-8.

Russell, G., Golding, J., Norwich, B., Emond, A., Ford, T., \& Steer, C. (2012). Social and behavioural outcomes in children diagnosed with autism spectrum disorders: a longitudinal cohort study. Journal of Child Psychology and Psychiatry, 53(7), 735-744. https://doi.org/ 10.1111/j.1469-7610.2011.02490.x.

Shah, P., Livingston, L. A., Callan, M. J., \& Player, L. (2019). Trait Autism is a better predictor of empathy than alexithymia. Journal of Autism and Developmental Disorders, 49(10), 3956-3964. https://doi.org/10.1007/s10803-019-04080-3.

Sheppard, E., Pillai, D., Wong, G. T.-L., Ropar, D., \& Mitchell, P. (2016). How easy is it to read the minds of people with autism spectrum disorder? Journal of Autism and Developmental Disorders, 46(4), 1247-1254. https://doi.org/10.1007/s10803-015-2662-8.

Shivers, C. M. (2019). Empathy and perceptions of their brother or sister among adolescent siblings of individuals with and without autism spectrum disorder. Research in Developmental Disabilities, 92, 103451. https://doi.org/10.1016/j.ridd.2019.103451.

Shivers, C. M., Jackson, J. B., \& McGregor, C. M. (2019). Functioning among typically developing siblings of individuals with autism spectrum disorder: a meta-analysis. Clinical Child and Family Psychology Review, 22(2), 172-196. https://doi.org/10.1007/ s10567-018-0269-2.

Sigman, M. D., Kasari, C., Kwon, J.-H., \& Yirmiya, N. (1992). Responses to the negative emotions of others by autistic, mentally retarded, and normal children. Child Development, 63(4), 796-807. https://doi.org/10.1111/j.1467-8624.1992.tb01662.x.

Simonoff, E., Pickles, A., Charman, T., Chandler, S., Loucas, T., \& Baird, G. (2008). Psychiatric disorders in children with autism spectrum disorders: prevalence, comorbidity, and associated factors in a population-derived sample. Journal of the American Academy of Child \& Adolescent Psychiatry, 47(8), 921-929. https://doi.org/10. 1097/CHI.0b013e318179964f.

Song, Y., Nie, T., Shi, W., Zhao, X., \& Yang, Y. (2019). Empathy impairment in individuals with autism spectrum conditions from a multidimensional perspective: a meta-analysis. Frontiers in Psychology, 10. https://doi.org/10.3389/fpsyg.2019.01902. 
Stang, A. (2010). Critical evaluation of the Newcastle-Ottawa scale for the assessment of the quality of nonrandomized studies in metaanalyses. European Journal of Epidemiology, 25(9), 603-605. https://doi.org/10.1007/s10654-010-9491-z.

Stone, L. L., Otten, R., Engels, R. C. M. E., Vermulst, A. A., \& Janssens, J. M. A. M. (2010). Psychometric properties of the parent and teacher versions of the Strengths and Difficulties Questionnaire for 4- to 12year-olds: a review. Clinical Child and Family Psychology Review, 13(3), 254-274. https://doi.org/10.1007/s10567-010-0071-2.

Tager-Flusberg, H. (2007). Evaluating the theory-of-mind hypothesis of autism. Current Directions in Psychological Science, 16(6), 311315. https://doi.org/10.1111/j.1467-8721.2007.00527.x.

Telle, N.-T., \& Pfister, H.-R. (2016). Positive empathy and prosocial behavior: a neglected link. Emotion Review, 8(2), 154-163. https:// doi.org/10.1177/1754073915586817.

Tick, B., Bolton, P., Happé, F., Rutter, M., \& Rijsdijk, F. (2016). Heritability of autism spectrum disorders: a meta-analysis of twin studies. Journal of Child Psychology and Psychiatry, 57(5), 585595. https://doi.org/10.1111/jcpp.12499.

Tomeny, T. S., Barry, T. D., \& Bader, S. H. (2012). Are typicallydeveloping siblings of children with an autism spectrum disorder at risk for behavioral, emotional, and social maladjustment? Research in Autism Spectrum Disorders, 6(1), 508-518. https:// doi.org/10.1016/j.rasd.2011.07.012.

Tomeny, T. S., Barry, T. D., Fair, E. C., \& Riley, R. (2017). Parentification of adult siblings of individuals with autism spectrum disorder. Journal of Child and Family Studies, 26(4), 1056-1067. https://doi.org/10.1007/s10826-016-0627-y.

Tsai, H.-W. J., Cebula, K., \& Fletcher-Watson, S. (2016). Influences on the psychosocial adjustment of siblings of children with autism spectrum disorder in Taiwan and the United Kingdom. Research in Autism Spectrum Disorders, 32, 115-129. https://doi.org/10. 1016/j.rasd.2016.09.007.
Tsang, T., Gillespie-Lynch, K., \& Hutman, T. (2016). Theory of Mind indexes the broader autism phenotype in siblings of children with autism at school age. Autism Research and Treatment, 2016, e6309189. https://doi.org/10.1155/2016/6309189.

Tudor, M. E., Rankin, J., \& Lerner, M. D. (2018). A model of family and child functioning in siblings of youth with autism spectrum disorder. Journal of Autism and Developmental Disorders, 48(4), 1210 1227. https://doi.org/10.1007/s10803-017-3352-5.

Walton, K. M., \& Ingersoll, B. R. (2015). Psychosocial adjustment and sibling relationships in siblings of children with autism spectrum disorder: risk and protective factors. Journal of Autism and Developmental Disorders, 45(9), 2764-2778. https://doi.org/10. 1007/s10803-015-2440-7.

Wells, G. A., Shea, B., O'Connell, D., Peterson, J., Welch, V., Losos, M., \& Tugwell, P. (2019). The Newcastle-Ottawa Scale (NOS) for assessing the quality of nonrandomised studies in meta-analyses. http://www.ohri.ca/programs/clinical_epidemiology/oxford.asp

Westby, C., \& Robinson, L. (2014). A developmental perspective for promoting theory of mind. Topics in Language Disorders, 34(4), 362-382. https://doi.org/10.1097/TLD.0000000000000035.

Zahn-Waxler, C., Radke-Yarrow, M., Wagner, E., \& Chapman, M. (1992). Development of concern for others. Developmental Psychology, 28(1), 126-136. https://doi.org/10.1037/0012-1649. 28.1.126.

Zhao, X., Li, X., Song, Y., \& Shi, W. (2019). Autistic traits and prosocial behaviour in the general population: test of the mediating effects of trait empathy and state empathic concern. Journal of Autism and Developmental Disorders, 49(10), 3925-3938. https://doi.org/10. 1007/s10803-018-3745-0.

Publisher's Note Springer Nature remains neutral with regard to jurisdictional claims in published maps and institutional affiliations. 